\title{
Retraction Note: Selective laser melting of G-surface lattice: forming process and boiling heat transfer characteristics
}

\author{
Jianrui Zhang • Pei Li • Bo Qian · Bo Li · \\ Zhijun Qiu • Fuzhen Xuan
}

Published online: 12 August 2021

(C) Springer Nature B.V. 2021

\section{Retraction Note to: J Nanopart Res (2020) 22:178 https://doi.org/10.1007/s11051-020-04914-7}

The Editor-in-Chief and the Publisher have retracted this article. The article was accepted as part of a guest-edited special issue in Journal of Nanoparticle Research. Before the special issue was finalized, the Editor-in-Chief detected problems with editorial handling and peer review and decided not to proceed with the special issue [1].

Post publication peer review found that this article is out of scope for the journal, which focuses on original contributions on nanoscale phenomena and processes, and does not meet the standards required by the journal.
None of the authors responded to correspondence from the publisher about this retraction.

\section{Reference}

1. Pinna N, Clavel G, Roco MC (2020) The Journal of Nanoparticle Research victim of an organized rogue editor network! J Nanopart Res 22:376. https://doi.org/10.1007/ s11051-020-05094-0

Publisher's Note Springer Nature remains neutral with regard to jurisdictional claims in published maps and institutional affiliations.

The original article can be found online at https://doi.org/ 10.1007/s11051-020-04914-7.

J. Zhang · P. Li · B. Qian $(\bowtie) \cdot$ B. Li · F. Xuan $(\bowtie)$

School of Mechanical and Power Engineering, East China

University of Science and Technology, Shanghai 200237,

China

e-mail: qianbo@ecust.edu.cn

F. Xuan

e-mail: fzxuan@ecust.edu.cn

J. Zhang · Z. Qiu

School of Mechanical, Materials, Mechatronic and Biomedical Engineering, University of Wollongong,

Wollongong, Australia 